\title{
Optical coherence tomography assessment of new- generation mesh-covered stents after carotid stenting
}

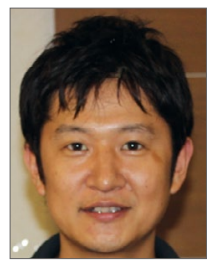

Tomoyuki Umemoto ${ }^{1 *}, \mathrm{MD}$; Gianmarco de Donato², MD; Andrea Pacchioni ${ }^{3}, \mathrm{MD}$; Bernhard Reimers ${ }^{4}, \mathrm{MD}$; Giuseppe Ferrante ${ }^{4}, \mathrm{MD}$, PhD; Mitsuaki Isobe', MD, PhD; Carlo Setacci², MD

1. Department of Cardiovascular Medicine, Tokyo Medical and Dental University, Tokyo, Japan; 2. Department of Surgery, Vascular and Endovascular Surgery Unit, University of Siena, Siena, Italy; 3. Department of Cardiology, Ospedale Civile di Mirano, Mirano, Italy; 4. Department of Cardiovascular Medicine, Humanitas Clinical and Research Institute, Rozzano, Milan, Italy

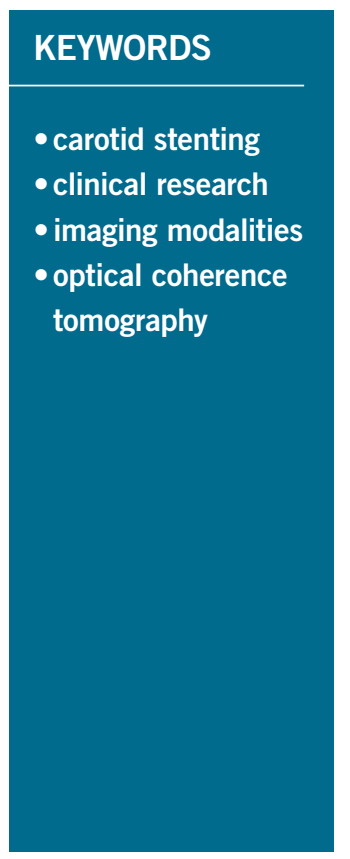

\begin{abstract}
Aims: The aim of this study was to identify the findings (by optical coherence tomography [OCT]) after carotid artery stenting (CAS) with two different types of new-generation mesh-covered stent.

Methods and results: Sixteen consecutive patients undergoing CAS with mesh-covered stents and highdefinition OCT image acquisition were enrolled in the study. Cross-sectional OCT images for the presence of strut malapposition (SM) and plaque prolapse (PP) were evaluated using a proximal or distal embolic protection device (EPD). CGuard stents were used in 11 patients (68.8\%) and RoadSaver stents in five (31.2\%). With OCT analysis, the incidence of SM was $20.5 \%$ for CGuard vs. $26.8 \%$ for RoadSaver, $\mathrm{p}=0.26$, and the incidence of PP was $10.8 \%$ for CGuard vs. $20.7 \%$ for RoadSaver, $\mathrm{p}=0.05$. No neurological complications (stroke/TIA) occurred during the procedural and post-procedural periods.
\end{abstract}

Conclusions: The OCT findings of two different types of mesh-covered stent after CAS were obtained safely. Our work indicates that current mesh-covered carotid stents may show differences in SM and PP. The effect of stent design and implantation technique on OCT findings post CAS, and their relation to longterm clinical outcomes, require further evaluation.

\footnotetext{
*Corresponding author: Department of Cardiovascular Medicine, Tokyo Medical and Dental University, 1-5-45, Yushima, Bunkyo-ku, Tokyo, 113-8519, Japan.E-mail: t.umemoto@gmail.com
} 


$\begin{array}{ll}\text { Abbreviations } \\ \text { CAS } & \text { carotid artery stenting } \\ \text { CCA } & \text { common carotid artery } \\ \text { ICA } & \text { internal carotid artery } \\ \text { OCT } & \text { optical coherence tomography } \\ \text { PP } & \text { plaque prolapse } \\ \text { SM } & \text { strut malapposition } \\ \text { TIA } & \text { transient ischaemic attack }\end{array}$

\section{Introduction}

Carotid artery stenting (CAS) has become an alternative therapy to carotid endarterectomy (CEA) $)^{1,2}$. With an improvement in embolic protection devices, the incidence of procedural embolic events has been dramatically reduced ${ }^{3-5}$. Recently, plaque prolapse (PP) after stent placement has been suggested as one of the major causes of post-procedural ischaemic complications ${ }^{6,7}$.

With intravascular imaging modalities, such as intravascular ultrasound (IVUS) or optical coherence tomography (OCT), the interaction between a plaque and stent strut can be evaluated. The safety and feasibility of OCT applied to carotid arteries have been reported recently with both an occlusive and a non-occlusive technique $^{8,9}$. We previously reported the incidence of SM and PP of conventional carotid stents assessed by $\mathrm{OCT}^{8}$.

At present, several different types of new-generation mesh-covered stent have been developed and are expected to have potential for reducing PP after stenting ${ }^{10,11}$. Clinical reports have emerged that may indicate the superiority of mesh-covered stents over conventional stents after $\mathrm{CAS}^{12,13}$, but any potential long-term clinical outcome differences between particular mesh-covered stent designs remain unknown. Recent work in non-consecutive RoadSaver ${ }^{\mathrm{TM}}$ (Terumo Corp., Tokyo, Japan) stent implants evaluated with OCT indicated a relatively low incidence of PP $(7.7 \%)^{14}$. Nevertheless, the incidence of stent malapposition (SM) and PP with different mesh-covered stent designs using OCT assessment has not been systematically determined.

We performed an OCT assessment of two different types of mesh-covered stent after CAS.

\section{Editorial, see page 1266}

\section{Methods \\ STUDY DESIGN}

This prospective study was performed at two centres (Department of Cardiology, Mirano General Hospital, Mirano, Italy, and Department of Surgery, Vascular and Endovascular Surgery Unit, University of Siena, Siena, Italy), including 16 consecutive patients undergoing CAS with OCT from October 2014 to July 2015. The study protocol was approved by the ethics committee of each hospital and written informed consent was obtained from all patients. Inclusion criteria were either a $>80 \%$ asymptomatic internal carotid artery (ICA) stenosis or a $>50 \%$ symptomatic ICA stenosis (North American Symptomatic Carotid Endarterectomy Trial [NASCET] criteria) in patients already considered eligible for endovascular treatment. Demographic variables, clinical figures, and intraoperative and follow-up data were prospectively collected by the operating team in a dedicated database. Independent neurological examinations of all patients were performed before the intervention, at discharge, and at 30 days after the procedure. No routine post-procedural cerebral imaging was performed; this was scheduled for potential cases with neurological complications only.

\section{CAS TECHNIQUE}

CAS was performed with either a proximal or a distal protection method. In patients in whom a proximal protection method was employed, the Mo.Ma ${ }^{\mathrm{TM}}$ Ultra (Medtronic, Santa Rosa, CA, USA) cerebral protection system was used. In patients in whom a distal protection method was employed, either a Spider FX'M (Medtronic) (five cases) or a FilterWire EZ ${ }^{\mathrm{TM}}$ embolic protection device (Boston Scientific, Marlborough, MA, USA) (two cases) was used. Under embolic protection, OCT scans were performed using either an occlusive or a non-occlusive flush. The stent diameter was selected according to the common carotid artery (CCA) diameter (mean oversize of $1 \mathrm{~mm}$ ), while the stent length was calculated to cover the entire carotid lesion (at least $0.5 \mathrm{~cm}$ below and $0.5 \mathrm{~cm}$ above the target lesion). Residual stenosis $<30 \%$ was considered acceptable for technical success.

\section{NEW-GENERATION CAROTID STENTS: MESH STENTS}

The CGuard ${ }^{\mathrm{TM}}$ Carotid Embolic Prevention System (InspireMD, Tel Aviv, Israel) and the RoadSaver Carotid Artery Stent System were used in the present study. Both new-generation mesh-covered stents have a different design from conventional stents as they possess micro-mesh, but they differ from one another in design details. The CGuard stent micro-mesh, made of polyethylene terephthalate (PET), is positioned outside the widely open-cell design stent frame (free cell area of $\left.21.66 \mathrm{~mm}^{2}\right)^{13,15}$. Its strut thickness is $240 \pm 12 \mu \mathrm{m}$. The fibre size and pore size of the PET mesh are $20 \mu \mathrm{m}$ and $165 \mu \mathrm{m}$, respectively. In contrast, the RoadSaver stent has micro-mesh made of nitinol placed inside the closedcell design stent frame. The stent frame strut thickness is $180 \mu \mathrm{m}$, while the metal mesh strut size and pore size are $42 \mu \mathrm{m}$ and $375 \mu \mathrm{m}$, respectively ${ }^{10}$. The third current mesh-covered carotid stent design, the Gore carotid stent (W.L. Gore \& Associates, Flagstaff, AZ, USA) ${ }^{16}$ was not available for our evaluation as its use was limited to the US SCAFFOLD study.

\section{THE OCT TECHNIQUE}

Carotid OCT images were acquired following dilation of the stent. The optical fibre of the LightLab FD-OCT system (St. Jude Medical, St. Paul, MN, USA) used for the investigation was encapsulated within a rotating torque wire (0.014-inch compatible) built in a rapid-exchange $2.6 \mathrm{Fr}$ catheter compatible with a $6 \mathrm{Fr}$ guiding catheter. It acquires 100 frames $\mathrm{s}^{-1}$, scanning a $55 \mathrm{~mm}$ artery segment in $2.7 \mathrm{~s}$ (pullback speeds up to $20 \mathrm{~mm} \mathrm{~s}^{-1}$ ). OCT evaluation was performed both in patients receiving a distal filter and in those with proximal protection in accordance with different protocols which have been described elsewhere ${ }^{8,9}$. 


\section{QUALITATIVE AND QUANTITATIVE ASSESSMENT OF OCT IMAGES}

All OCT frames were analysed off-line in a dedicated laboratory by two independent physicians. OCT images were judged of good quality according to a previously reported protocol based on the accuracy of vessel wall identification ${ }^{17}$. OCT images after stent placement and dilation were specifically reviewed and analysed in each patient. In particular, cross-sectional OCT images within the stented segment of the ICA were evaluated at $1 \mathrm{~mm}$ intervals for the presence of both SM and PP (Figure 1). A strut was defined as "malapposed" when the distance between vessel wall and the strut surface was $>200 \mu \mathrm{m}$ (Figure 2). Malapposition was defined as at least five malapposed struts in a single slice. PP after stenting was defined as tissue prolapse more than $300 \mu \mathrm{m}$ from the stent struts (Figure 3).

\section{ENDPOINTS}

The primary endpoints were the incidences of SM and PP as detected by OCT, according to the implanted stent. Secondary endpoints included the presence of either stroke or death at 30 days and any in-hospital adverse events.

\section{STATISTICAL ANALYSIS}

Continuous variables are presented as median (range) or mean \pm standard deviation (SD), and Mann-Whitney and Student's t-tests were used as appropriate. Differences in categorical variables were assessed using the chi-square and Fisher's exact tests as appropriate. Throughout the analysis, a two-tailed level of 0.05

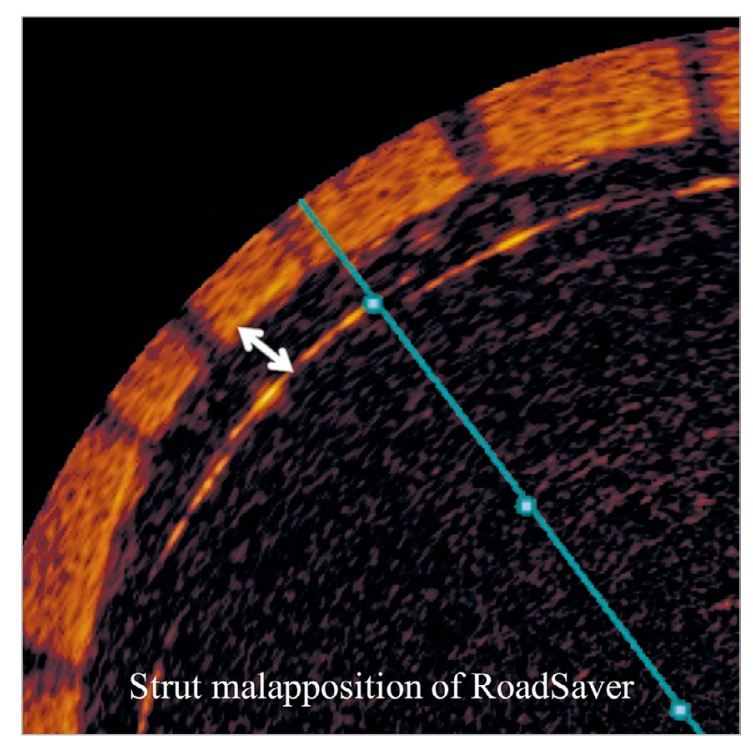

Figure 2. Illustration of strut malapposition definition. A strut was defined as malapposed when the distance from endoluminal strut border to vessel surface measured was $>200 \mu \mathrm{m}$.

was used as the threshold for determining statistical significance; p-values were not adjusted for the various statistical tests conducted. All statistical analyses were performed using the statistical software package GraphPad Prism 7.0a for Mac OS X (GraphPad Software Inc., San Diego, CA, USA).

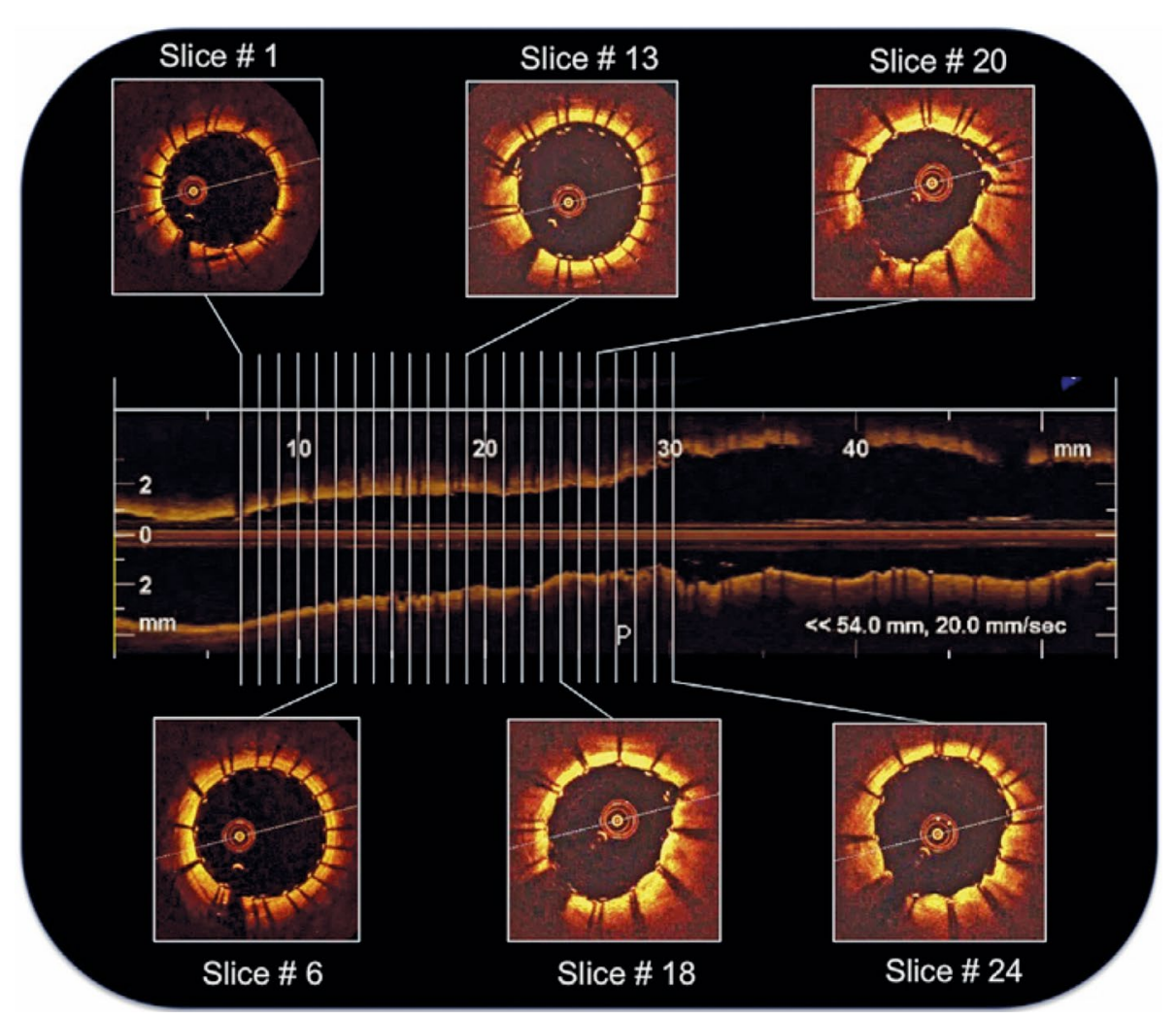

Figure 1. Analysis of cross-sectional OCT images within the stented segment of the internal carotid artery evaluated at $1 \mathrm{~mm}$ intervals. 


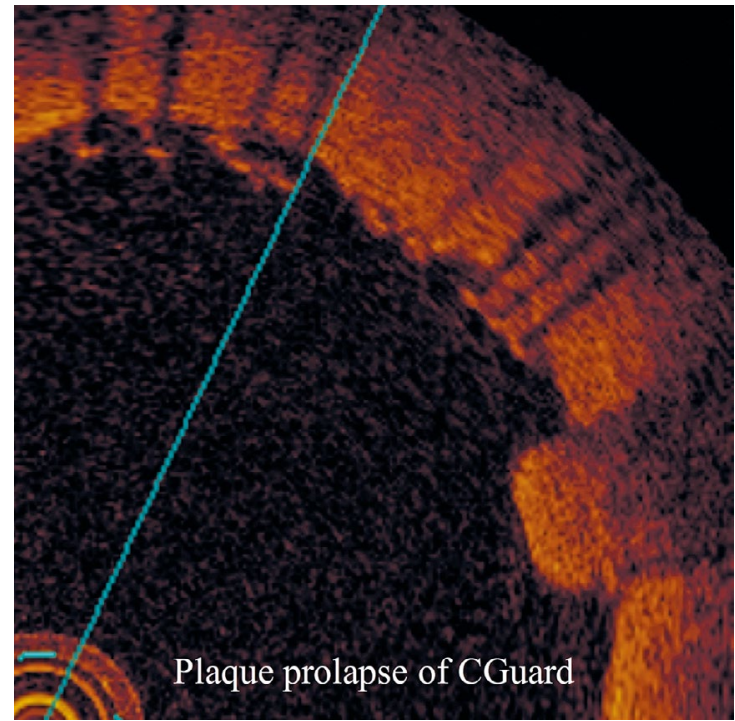

Figure 3. Illustration of plaque prolapse definition. PP was defined as tissue prolapse more than $300 \mu \mathrm{m}$ from the stent strut level.

\section{Results}

\section{PROCEDURAL RESULTS}

CAS with OCT image acquisitions was performed in all 16 patients. Completed angiograms revealed successful revascularisation and $<30 \%$ residual stenosis in each case. The CGuard stent was used in 11 procedures $(68.7 \%)$ and the RoadSaver stent in five $(31.3 \%)$. Table 1 summarises the patients' demographic data, neurological histories, and carotid plaque characteristics. The lesion characteristics of both stents are shown in Table 2. No technical or

Table 1. Patient characteristics.

\begin{tabular}{|l|c|c|c|c|}
\hline & $\begin{array}{c}\text { Total } \\
\text { population } \\
(\mathbf{n = 1 6 )}\end{array}$ & $\begin{array}{c}\text { CGuard } \\
(\mathbf{n = 1 1 )}\end{array}$ & $\begin{array}{c}\text { RoadSaver } \\
(\mathbf{n = 5})\end{array}$ & $\boldsymbol{p}$-value \\
\hline Male & $15(94 \%)$ & $10(91 \%)$ & $5(100 \%)$ & 1 \\
\hline Age, years & $75 \pm 7.5$ & $76 \pm 7.7$ & $73 \pm 6.9$ & 0.72 \\
\hline Symptomatic lesion & $3(19 \%)$ & $3(27 \%)$ & $0(0 \%)$ & 0.51 \\
\hline Hypertension & $11(69 \%)$ & $9(82 \%)$ & $2(40 \%)$ & 0.24 \\
\hline Diabetes mellitus & $6(37.5 \%)$ & $3(27 \%)$ & $3(60 \%)$ & 0.3 \\
\hline Smoker & $2(12.5 \%)$ & $2(18 \%)$ & $0(0 \%)$ & 1 \\
\hline Dyslipidaemia & $10(62.5 \%)$ & $8(73 \%)$ & $2(40 \%)$ & 0.3 \\
\hline CAD & $6(37.5 \%)$ & $3(27 \%)$ & $3(60 \%)$ & 0.3 \\
\hline Renal failure & $2(12.5 \%)$ & $1(9 \%)$ & $1(20 \%)$ & 1 \\
\hline $\begin{array}{l}\text { Peripheral arterial } \\
\text { disease }\end{array}$ & $1(6 \%)$ & $1(9 \%)$ & $0(0 \%)$ & 1 \\
\hline $\begin{array}{l}\text { Side of carotid } \\
\text { lesion (right) }\end{array}$ & $6(37.5 \%)$ & $4(36 \%)$ & $2(40 \%)$ & 1 \\
\hline $\begin{array}{l}\text { Restenosis after } \\
\text { CEA }\end{array}$ & $0(0 \%)$ & $0(0 \%)$ & $0(0 \%)$ & 1 \\
\hline $\begin{array}{l}\text { Continuous data are presented as mean } \pm \text { standard deviation; categorical } \\
\text { data are given as counts (percentage). CAD: coronary artery disease; } \\
\text { CEA: carotid endarterectomy }\end{array}$ & & \\
\hline
\end{tabular}

Table 2. Lesion characteristics by quantitative angiography.

\begin{tabular}{|l|c|c|c|l|}
\hline & $\begin{array}{c}\text { Total } \\
\text { population } \\
(\mathbf{n = 1 6 )}\end{array}$ & $\begin{array}{c}\text { CGuard } \\
(\mathbf{n}=11)\end{array}$ & $\begin{array}{c}\text { RoadSaver } \\
(\mathbf{n}=5)\end{array}$ & $\boldsymbol{p}$-value \\
\hline \% stenosis & $81 \pm 14$ & $81 \pm 16$ & $81 \pm 5$ & 0.98 \\
\hline $\begin{array}{l}\text { Contralateral } \\
\text { occlusion }\end{array}$ & $2(13 \%)$ & $2(18 \%)$ & $0(0 \%)$ & 1 \\
\hline $\begin{array}{l}\text { Minimal lumen } \\
\text { diameter }\end{array}$ & $1.4 \pm 0.6$ & $1.5 \pm 0.8$ & $1.4 \pm 0.4$ & 0.8 \\
\hline Lesion length, mm & $22.0 \pm 5.8$ & $22.3 \pm 6.6$ & $20.0 \pm 3.3$ & 0.48 \\
\hline $\begin{array}{l}\text { Proximal reference, } \\
\text { mm }\end{array}$ & $8.0 \pm 0.8$ & $8.0 \pm 0.8$ & $8.1 \pm 0.7$ & 0.78 \\
\hline $\begin{array}{l}\text { Distal reference, } \\
\text { mm }\end{array}$ & $5.1 \pm 0.9$ & $5.2 \pm 1.0$ & $5.0 \pm 0.4$ & 0.69 \\
\hline Continus & &
\end{tabular}

Continuous data are presented as mean \pm standard deviation; categorical data are given as counts (percentage).

neurological complications occurred during OCT pullbacks. Table 3 shows the characteristics of the stent procedures. Technical success was achieved in all patients. No major procedural or post-procedural complications occurred in the study population (any TIA/ stroke/death $0 \%$ at 30 days and at six months). The OCT images acquired after stent placement and dilation were judged in all cases to be of appropriate quality to allow the qualitative and quantitative assessment of the primary endpoints of the study.

\section{OCT ANALYSIS}

OCT analysis within the stented segment of the ICA at $1 \mathrm{~mm}$ intervals produced a mean of $16 \pm 4$ slices for each patient (Figure 1). A total of 248 cross-sectional OCT images (166 images for CGuard and 82 for RoadSaver) were analysed to assess the incidence of

Table 3. Procedure characteristics.

\begin{tabular}{|c|c|c|c|c|c|}
\hline & $\begin{array}{c}\text { Total } \\
\text { population } \\
(n=16)\end{array}$ & $\begin{array}{l}\text { CGuard } \\
(n=11)\end{array}$ & $\begin{array}{l}\text { RoadSaver } \\
(n=5)\end{array}$ & $p$-value \\
\hline \multirow[t]{2}{*}{ Introducer } & $8 \mathrm{Fr}$ & $5(31.3 \%)$ & $0(0 \%)$ & $5(100 \%)$ & \multirow{2}{*}{$<0.001$} \\
\hline & $9 \mathrm{Fr}$ & $11(68.8 \%)$ & $11(100 \%)$ & $0(0 \%)$ & \\
\hline \multirow[t]{2}{*}{ Protection } & Proximal & $9(56.3 \%)$ & $9(81.8 \%)$ & $0(0 \%)$ & \multirow{2}{*}{0.005} \\
\hline & Distal & $7(43.8 \%)$ & $2(18.2 \%)$ & $5(100 \%)$ & \\
\hline \multicolumn{2}{|c|}{ Predilatation } & $4(25 \%)$ & $4(36.4 \%)$ & $0(0 \%)$ & 0.24 \\
\hline \multicolumn{2}{|c|}{ Balloon diameter, mm } & $3.5 \pm 0.0$ & $3.5 \pm 0$ & - & - \\
\hline \multicolumn{2}{|c|}{ Balloon length, mm } & $16.3 \pm 2.2$ & $16.3 \pm 2.5$ & - & - \\
\hline \multicolumn{2}{|c|}{ Stent nominal diameter, mm } & $8.2 \pm 0.8$ & $8.1 \pm 0.9$ & $8.3 \pm 0.5$ & 1 \\
\hline \multicolumn{2}{|c|}{ Nominal stent length, $\mathrm{mm}$} & $32.4 \pm 6.2$ & $35 \pm 5.2$ & $27.5 \pm 2.9 *$ & 0.02 \\
\hline \multicolumn{2}{|c|}{ Post-dilatation } & $16(100 \%)$ & $11(100 \%)$ & $5(100 \%)$ & 1 \\
\hline \multicolumn{2}{|c|}{ Balloon diameter, $\mathrm{mm}$} & $5.3 \pm 0.4$ & $5.4 \pm 0.4$ & $5 \pm 0$ & 0.21 \\
\hline \multicolumn{2}{|c|}{ Balloon length, mm } & $20.9 \pm 3.6$ & $21.5 \pm 4.7$ & $20 \pm 0$ & 0.89 \\
\hline \multicolumn{2}{|c|}{ Procedural time, min } & $61 \pm 24.9$ & $66.5 \pm 28.0$ & $41.3 \pm 4.8$ & 0.04 \\
\hline \multicolumn{2}{|c|}{ Contrast, $\mathrm{mL}$} & $82.8 \pm 34.1$ & $93.5 \pm 38.7$ & $55 \pm 13$ & 0.13 \\
\hline \multicolumn{6}{|c|}{$\begin{array}{l}\text { Continuous data are presented as mean } \pm \text { standard deviation; categorical data are given as } \\
\text { counts (percentage). *Wissgott et a }{ }^{10} \text {. Total contrast use and total time for the CAS } \\
\text { procedure itself and imaging are provided. }\end{array}$} \\
\hline
\end{tabular}


SM and PP. Mean number of per-stent OCT images was $15.1 \pm 4.3$ for CGuard and $16.4 \pm 1.9$ for RoadSaver. Figure 4 shows the incidence of SM after stenting with the CGuard and RoadSaver stents. The incidence of SM was $20.5 \%$ for CGuard vs. $26.8 \%$ for RoadSaver, $\mathrm{p}=0.26$. Figure 5 shows the incidence of PP after stenting with the CGuard and RoadSaver stents. The incidence of PP was $10.8 \%$ for CGuard vs. $20.7 \%$ for RoadSaver, $\mathrm{p}=0.05$. Representative OCT images of SM and PP in both stents are shown in Figure 6.

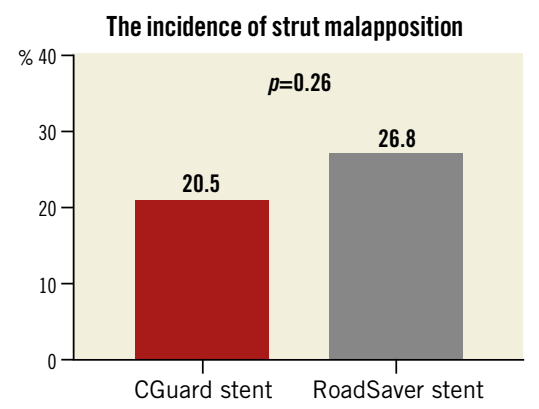

Figure 4. The incidence of SM in the CGuard and RoadSaver stents.

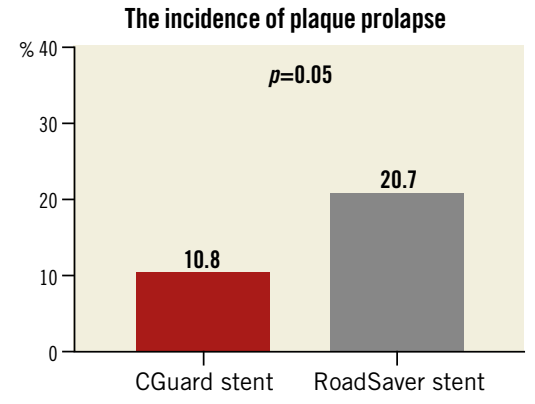

Figure 5. The incidence of PP in the CGuard and RoadSaver stents.

\section{Discussion}

This is the first study using OCT to assess systematically different types of mesh-covered carotid stent. This study using OCT was performed without any procedural or post-procedural complications. We provide novel observations with regard to strut malapposition and plaque prolapse in different mesh-covered stent designs.

With the OCT assessment after CAS, we performed a detailed analysis of SM and PP in mesh-covered stents. There are some
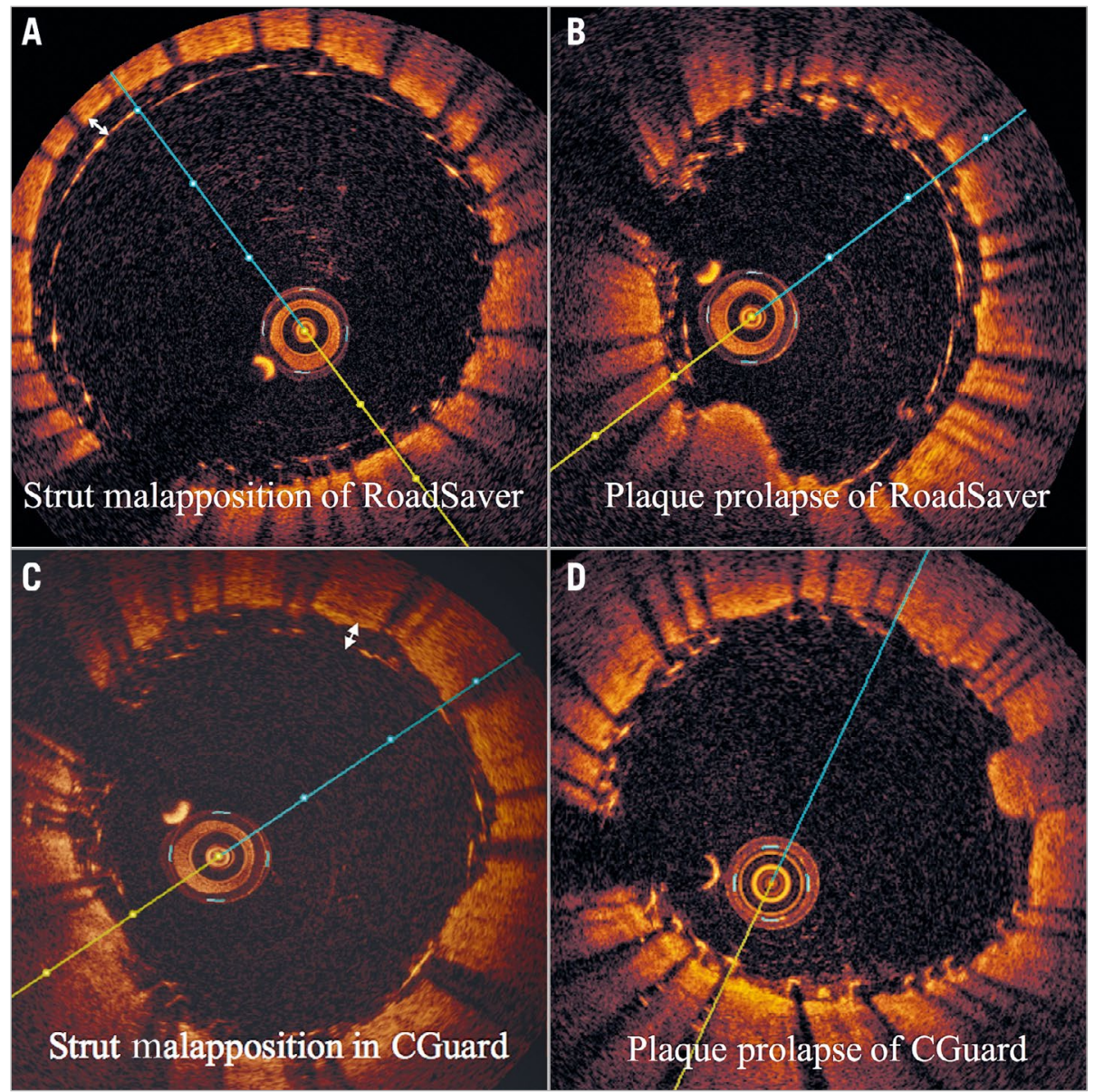

Figure 6. Examples of strut malapposition and plaque prolapse in the RoadSaver and CGuard stents. A) SM in the RoadSaver stent, B) PP in the RoadSaver stent, C) SM in the CGuard stent, D) PP in the CGuard stent. 
reports evaluating conventional carotid stents by intravascular modalities after stenting ${ }^{18-21}$. Now, the number of studies using OCT is increasing because this newer light-based modality can deliver resolution to 10 to $15 \mu \mathrm{m}$, giving it the highest imaging resolution of any currently available vascular imaging modality ${ }^{9,17,22-25}$. Yoshimura et al reported that OCT can detect a PP after CAS which is difficult to view even by IVUS ${ }^{26}$. Shindo et al presented a single case report about OCT imaging of a mesh-covered stent ${ }^{27}$. Therefore, in this study we also used OCT for assessment of the findings after CAS. We show the safety and feasibility of assessing the stent-vessel interaction of mesh-covered stents as comparable to that reported for conventional carotid stents ${ }^{8}$. Unexpectedly, we found that PP occurred even with mesh-covered stents. This may be expected because mesh-covered stents are not "fully covered" stents. Plaque can prolapse through the pores of the mesh at a range of $165-375 \mu \mathrm{m}$. PP is induced by many factors. One of the reasons for PP with mesh-covered stents can be attributed to plaque morphology. Soft and vulnerable plaque easily protrudes through the strut and mesh ${ }^{28,29}$. Other reasons may be related to stent implantation technique, including use (vs. no use) of a postdilatation balloon, its size and maximal inflation pressure.

Embolic complications after CAS were seen not only in the post-procedural period but also in the procedural period ${ }^{1,7,30}$. Thrombus formation in the stent induced by either an insufficient antiplatelet effect or SM can be the reason for post-procedural embolic complications. Hashimura et al successfully showed that PP can occur even after the procedure in cases with conventional carotid stents ${ }^{31}$. This "late PP" can also be the cause of post-procedural embolic complications. Because no evaluation by either ultrasound or CT angiography was carried out in the post-procedural period in our study, it is still unknown whether the late PP problem will occur even with mesh-covered stents. However, with the images obtained in our study which showed prolapsed plaque remaining between the double layer (Figure 7), the plaque sealing effect of the mesh can be expected to persist not only in the procedural period but also in the post-procedural period.

In this study, the incidence of PP was $10.5 \%$ for CGuard vs. $20.7 \%$ for RoadSaver, $p=0.05$. As the designs of these two stents are completely different, some of the differences found with OCT are likely to be stent design-dependent. What appears as "PP" with CGuard could be a MicroNet ${ }^{\mathrm{TM}}$-covered "PP". This might be different from the RoadSaver, particularly when the plaque goes through the inner nitinol mesh, which is uncovered "PP". It is not easy to confirm this hypothesis because of OCT resolution $(10-15 \mu \mathrm{m})$. The MicroNet fibres $(20 \mu \mathrm{m})$ of CGuard cannot be detected clearly in contrast to the nitinol inner mesh layer struts $(42 \mu \mathrm{m})$ in the RoadSaver. Indeed, histology images suggest that elastic, non-metallic, mesh fibres may be present inside the PP, providing a cover to the PP inside the lumen ${ }^{15}$. Other reasons for the differences may be the implantation technique or OCT imaging under a distal vs. a proximal embolic protection device (EPD). It appears that it may be more difficult to remove the blood completely under the proximal EPD and thus this method may be more

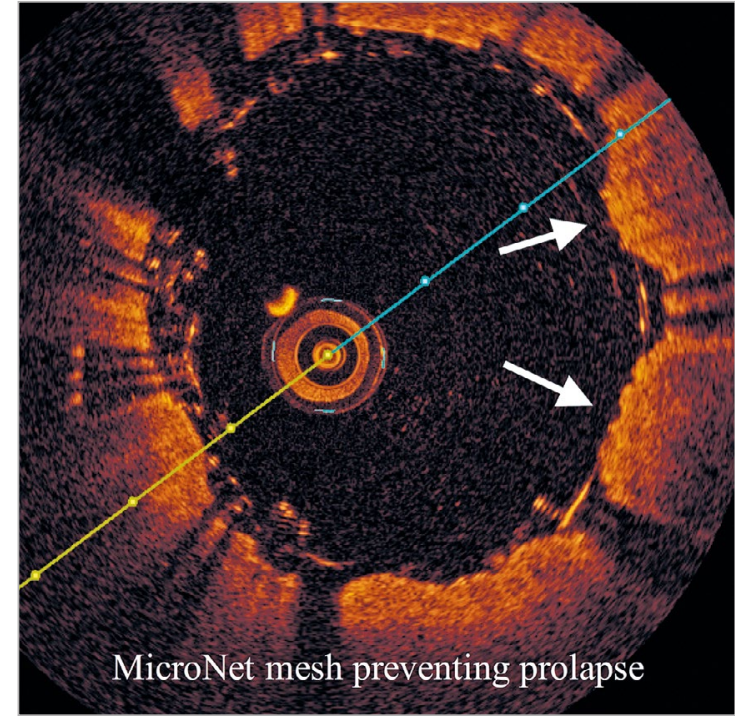

Figure 7. The plaque prolapse appears to be covered with MicroNet adapting its position between the metallic stent struts to the prolapsing plaque (white arrows)

prone to artefact. The incidence of SM was $20.5 \%$ for CGuard vs. $26.8 \%$ for RoadSaver, $\mathrm{p}=0.26$. SM would probably be influenced by stent design, vessel tortuosity and implantation technique $\mathrm{e}^{10,13,15}$.

Recently, Nerla et al reported a low rate of PP in patients treated with the RoadSaver stent detected by $\mathrm{OCT}^{14}$. The incidence of PP in our work (20.7\%) was higher compared with their data $(7.7 \%)$. This might be explained by the difference of analysis method (slice-based analysis vs. patient-based analysis).

As the structure of mesh-covered stents is completely different from that of conventional stents, the required duration of dual antiplatelet therapy (DAPT) is still unclear ${ }^{32}$. Mesh-covered stents have an additional material, structure of PET or nitinol, so the patients may require a longer period of DAPT. Long-term clinical and duplex ultrasound data on different mesh-covered stent designs are needed to determine the incidence of any clinically relevant thrombosis or restenosis.

We also compared these data of mesh-covered stents with the data of conventional stents as published in our previous study ${ }^{8}$. In the previous study, closed-cell design (CC) stents were used in 17 procedures, open-cell design (OC) stents in 13, and hybrid design (Hyb) stents in 10. A significant difference was noted in the incidence of SM among the five stent types $(\mathrm{p}<0.001)$. The incidence of SM in mesh-covered stents was intermediate between CC (29.8\%) and $\mathrm{OC}$ and $\mathrm{Hyb}$ (13.2\% and $14.8 \%$, respectively). A significant difference was also noted in the incidence of PP among the five stents $(\mathrm{p}<0.001)$. PP was more frequent in OC $(68.6 \%)$. Recently, Lin $\mathrm{R}$ et al reported an incidence of PP after CAS with conventional stents ranging from $49.1 \%$ to $65.5 \%{ }^{33}$. Thus, mesh-covered stents clearly appear to show less frequent PP than any of the conventional stents. Some clinical studies using mesh-covered stents have shown better clinical outcomes as compared with those in reports using 
conventional stents ${ }^{12,13}$. The results from our work provide some mechanistic explanation as to why mesh-covered stent use might be associated with improved clinical outcomes compared with those seen with conventional carotid stents.

\section{Limitations}

The present study has several limitations. First, this is an observational study with a small number of patients, and stent selection depended on physician discretion. We could evaluate limited consecutive cases depending on the availability of OCT imaging catheters in a non-sponsored study. Moreover, imbalanced comparison between 11 CGuard stents and five RoadSaver stents may have affected the statistics. Second, the clinical implications of SM and PP detected by OCT are still unknown. As no adverse clinical events occurred in the perioperative period, after 30 days, and at six months, on the basis of our small clinical cohort we cannot comment on the clinical significance of our findings. Recently, the CARENET study demonstrated the effectiveness of per-protocol diffusion-weighted magnetic resonance imaging (DW-MRI) in detecting the incidence and lesion volume with clinically silent minor periprocedural cerebral embolisation and near elimination of cerebral embolisation during stent healing up to 30 days ${ }^{11}$. Although DW-MRI imaging at 30 days would be the final demonstrator of the relevance of OCT-detected PP, we were not able to perform DW-MRI in our study cohort.

\section{Conclusions}

In conclusion, this study demonstrated detailed OCT findings in different mesh-covered carotid stent designs, indicating potential differences in SM and PP. Though the clinical relevance of OCTdetected SM and PP is unclear and longer-term follow-up will be needed, the present findings, taken in aggregate with our earlier work ${ }^{8}$, indicate that mesh-covered stents have the potential to minimise plaque protrusion - a pathologic finding the presence of which is related to the risk of periprocedural and post-procedural adverse neurologic events ${ }^{34}$.

\section{Impact on daily practice}

The use of mesh-covered carotid stents can reduce the incidence of PP after CAS compared with conventional stents. This provides one important mechanism in the potential of these devices to prevent embolic complications during CAS and throughout the stent healing period.

\section{Conflict of interest statement}

The authors have no conflicts of interest to declare.

\section{References}

1. Brott TG, Howard G, Roubin GS, Meschia JF, Mackey A, Brooks W, Moore WS, Hill MD, Mantese VA, Clark WM, Timaran CH, Heck D, Leimgruber PP, Sheffet AJ, Howard VJ, Chaturvedi S, Lal BK, Voeks JH, Hobson RW 2nd; CREST
Investigators. Long-Term Results of Stenting versus Endarterectomy for Carotid-Artery Stenosis. N Engl J Med. 2016;374:1021-31.

2. Rosenfield K, Matsumura JS, Chaturvedi S, Riles T, Ansel GM, Metzger DC, Wechsler L, Jaff MR, Gray W; ACT I Investigators. Randomized Trial of Stent versus Surgery for Asymptomatic Carotid Stenosis. N Engl J Med. 2016;374:1011-20.

3. ClairDG, Hopkins LN, Mehta M, Kasirajan K, Schermerhorn M, Schönholz C, Kwolek CJ, Eskandari MK, Powell RJ, Ansel GM; EMPiRE Clinical Study Investigators. Neuroprotection during carotid artery stenting using the GORE flow reversal system: 30-day outcomes in the EMPiRE Clinical Study. Catheter Cardiovasc Interv. 2010;77:420-9.

4. Ansel GM, Hopkins LN, Jaff MR, Rubino P, Bacharach JM, Scheinert D, Myla S, Das T, Cremonesi A; Investigators for the ARMOUR Pivotal Trial. Safety and effectiveness of the INVATEC MO.MA proximal cerebral protection device during carotid artery stenting: results from the ARMOUR pivotal trial. Catheter Cardiovasc Interv. 2010;76:1-8.

5. Nikas D, Reith W, Schmidt A, Duda S, Mathias K, Cremonesi A, Dill H, Formgren J, Pieniazek P, Musialek P, Hornung M, Sievert H, Reimers B. Prospective, multicenter European study of the GORE flow reversal system for providing neuroprotection during carotid artery stenting. Catheter Cardiovasc Interv. 2012;80:1060-8.

6. Cremonesi A, Setacci C, Manetti R, de Donato G, Setacci F, Balestra G, Borghesi I, Bianchi P, Castriota F. Carotid angioplasty and stenting: lesion related treatment strategies. EuroIntervention. 2005; 1:289-95.

7. Bosiers M, de Donato G, Deloose K, Verbist J, Peeters P, Castriota F, Cremonesi A, Setacci C. Does free cell area influence the outcome in carotid artery stenting? Eur J Vasc Endovasc Surg. 2007;33:135-41.

8. de Donato G, Setacci F, Sirignano P, Galzerano G, Cappelli A, Setacci C. Optical coherence tomography after carotid stenting: rate of stent malapposition, plaque prolapse and fibrous cap rupture according to stent design. Eur J Vasc Endovasc Surg. 2013;45: 579-87.

9. Secco GG, Cremonesi A, Amor M, Pistis G, Reimers B, Castriota F. Optical coherence tomography during carotid artery stenting: A new niche application? Int J Cardiol. 2015;187:372-3. 10. Wissgott C, Schmidt W, Brandt C, Behrens P, Andresen R. Preliminary Clinical Results and Mechanical Behavior of a New Double-Layer Carotid Stent. J Endovasc Ther. 2015;22:634-9.

11. Schofer J, Musiałek P, Bijuklic K, Kolvenbach R, Trystula M, Siudak Z, Sievert H. A Prospective, Multicenter Study of a Novel Mesh-Covered Carotid Stent: The CGuard CARENET Trial (Carotid Embolic Protection Using MicroNet). JACC Cardiovasc Interv. 2015;8:1229-34.

12. Bosiers M, Deloose K, Torsello G, Scheinert D, Maene L, Peeters P, Müller-Hülsbeck S, Sievert H, Langhoff R, Bosiers M, Setacci C. The CLEAR-ROAD study: evaluation of a new dual layer micromesh stent system for the carotid artery. EuroIntervention. 2016;12:e671-6. 
13. Musialek P, Mazurek A, Trystula M, Borratynska A, LesniakSobelga A, Urbanczyk M, Banys RP, Brzychczy A, Zajdel W, Partyka L, Zmudka K, Podolec P. Novel PARADIGM in carotid revascularisation: Prospective evaluation of All-comer peRcutaneous cArotiD revascularisation in symptomatic and Increased-risk asymptomatic carotid artery stenosis using CGuard ${ }^{\mathrm{TM}}$ MicroNetcovered embolic prevention stent system. EuroIntervention. 2016;12:e658-70.

14. Nerla R, Castriota F, Micari A, Sbarzaglia P, Secco GG, Ruffino MA, de Donato G, Setacci C, Cremonesi A. Carotid artery stenting with a new-generation double-mesh stent in three highvolume Italian centres: clinical results of a multidisciplinary approach. EuroIntervention. 2016;12:e677-83.

15. Wissgott C, Schmidt W, Brandt-Wunderlich C, Behrens P, Andresen R. Clinical Results and Mechanical Properties of the Carotid CGUARD Double-Layered Embolic Prevention Stent. $J$ Endovasc Ther. 2017;24:130-7.

16. Musialek P, Hopkins LN, Siddiqui AH. One swallow does not a summer make but many swallows do: Accumulating clinical evidence for nearly-eliminated peri-procedural and 30-day complications with mesh-covered stents transforms the carotid revascularisation field. Adv Interv Cardiol. 2017;13:95-106.

17. Setacci C, de Donato G, Setacci F, Galzerano G, Sirignano P, Cappelli A, Palasciano G. Safety and feasibility of intravascular optical coherence tomography using a nonocclusive technique to evaluate carotid plaques before and after stent deployment. J Endovasc Ther. 2012;19:303-11.

18. Clark DJ, Lessio S, O'Donoghue M, Schainfeld R, Rosenfield K. Safety and utility of intravascular ultrasound-guided carotid artery stenting. Catheter Cardiovasc Interv. 2004;63:355-62.

19. Diethrich EB, Pauliina Margolis M, Reid DB, Burke A, Ramaiah V, Rodriguez-Lopez JA, Wheatley G, Olsen D, Virmani R. Virtual histology intravascular ultrasound assessment of carotid artery disease: the Carotid Artery Plaque Virtual Histology Evaluation (CAPITAL) study. J Endovasc Ther. 2007;14:676-86.

20. Musialek P, Pieniazek P, Tracz W, Tekieli L, Przewlocki T, Kablak-Ziembicka A, Motyl R, Moczulski Z, Stepniewski J, Trystula M, Zajdel W, Roslawiecka A, Zmudka K, Podolec P. Safety of embolic protection device-assisted and unprotected intravascular ultrasound in evaluating carotid artery atherosclerotic lesions. Med Sci Monit. 2012;18:MT7-18.

21. Sangiorgi G, Bedogni F, Sganzerla P, Binetti G, Inglese L, Musialek P, Esposito G, Cremonesi A, Biasi G, Jakala J, Mauriello A, Biondi-Zoccai G. The Virtual histology In CaroTids Observational RegistrY (VICTORY) study: a European prospective registry to assess the feasibility and safety of intravascular ultrasound and virtual histology during carotid interventions. Int $J$ Cardiol. 2013;168:2089-93.

22. Reimers B, Nikas D, Stabile E, Favero L, Saccà S, Cremonesi A, Rubino P. Preliminary experience with optical coherence tomography imaging to evaluate carotid artery stents: safety, feasibility and techniques. EuroIntervention. 2011;7:98-105.
23. Jones MR, Attizzani GF, Given CA, Brooks WH, Costa MA, Bezerra HG. Intravascular frequency-domain optical coherence tomography assessment of atherosclerosis and stent-vessel interactions in human carotid arteries. AJNR Am J Neuroradiol. 2012; 33:1494-501.

24. Given CA 2nd, Attizzani GF, Jones MR, Ramsey CN 3rd, Brooks WH, Costa MA, Bezerra HG. Frequency-domain optical coherence tomography assessment of human carotid atherosclerosis using saline flush for blood clearance without balloon occlusion. AJNR Am J Neuroradiol. 2013;34:1414-8.

25. Jones MR, Attizzani GF, Given CA 2nd, Brooks WH, Ganocy SJ, Ramsey CN, Fujino Y, Bezerra HG, Costa MA. Intravascular frequency-domain optical coherence tomography assessment of carotid artery disease in symptomatic and asymptomatic patients. JACC Cardiovasc Interv. 2014;7:674-84.

26. Yoshimura S, Kawasaki M, Yamada K, Enomoto Y, Egashira Y, Hattori A, Nishigaki K, Minatoguchi S, Iwama T. Visualization of internal carotid artery atherosclerotic plaques in symptomatic and asymptomatic patients: a comparison of optical coherence tomography and intravascular ultrasound. AJNR Am J Neuroradiol. 2012;33:308-13.

27. Shindo S, Fujii K, Shirakawa M, Uchisa K, Sugiura Y, Saito S, Ando Y, Yoshimura S. Three-Dimensional Optical Frequency Domain Imaging Evaluation of Novel Dual-Layered Carotid Stent Implantation for Vulnerable Carotid Plaque. J Stroke Cerebrovasc Dis. 2016;25:e31-2.

28. Ferrero E, Ferri M, Viazzo A, Nessi F. Carotid stent removal of symptomatic plaque protrusion after carotid angioplasty stenting. Interact Cardiovasc Thorac Surg. 2010;11:254-6.

29. Setacci C, de Donato G, Setacci F, Chisci E, Cappelli A, Pieraccini M, Castriota F, Cremonesi A. Surgical management of acute carotid thrombosis after carotid stenting: a report of three cases. J Vasc Surg. 2005;42:993-6.

30. Fairman R, Gray WA, Scicli AP, Wilburn O, Verta P, Atkinson R, Yadav JS, Wholey M, Hopkins LN, Raabe R, Barnwell S, Green R; CAPTURE Trial Collaborators. The CAPTURE registry: analysis of strokes resulting from carotid artery stenting in the post approval setting: timing, location, severity, and type. Ann Surg. 2007;246:551-6.

31. Hashimura N, Mutoh T, Matsuda K, Matsumoto K. Evaluation and management of plaque protrusion or thrombus following carotid artery stenting. Neurol Med Chir (Tokyo). 2015;55:149-54.

32. Musialek P, Hopf-Jensen S. Carotid Artery Revascularization for Stroke Prevention: A New Era. J Endovasc Ther. 2017;24:138-48.

33. Liu R, Jiang Y, Xiong Y, Li M, Ma M, Zhu W, Yin Q, Li W, Xu G, Liu X. An Optical Coherence Tomography Assessment of Stent Strut Apposition Based on the Presence of Lipid-Rich Plaque in the Carotid Artery. J Endovasc Ther. 2015;22:942-9.

34. Kotsugi M, Takayama K, Myouchin K, Wada T, Nakagawa I, Nakagawa H, Taoka T, Kurokawa S, Nakase H, Kichikawa K. Carotid Artery Stenting: Investigation of Plaque Protrusion Incidence and Prognosis. JACC Cardiovasc Interv. 2017;10:824-31. 